\title{
American Thoracic Society 2019 Pediatric Core Curriculum
}

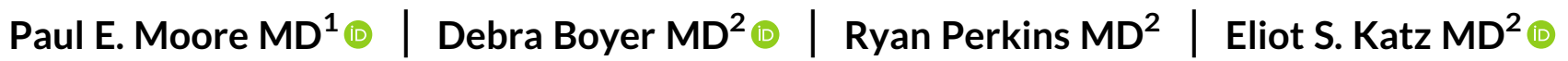 \\ Maria L. Castro-Codesal ${ }^{3}$ | Joanna E. MacLean ${ }^{3}$ | Nour Akil MD ${ }^{4}$ (] | \\ Charles R. Esther Jr MD, PhD ${ }^{4}$ | Jacob Kaslow MD $^{1}$ | Toby C. Lewis MD, MPH \\ Katie A. Krone $M D^{2}$ | Annabelle Quizon $M^{6} D^{6}$ Ryne Simpson $M^{7}$ | \\ Dan Benscoter DO ${ }^{7}$ | David R. Spielberg MD ${ }^{8} \odot$ | Ernestina Melicoff MD $^{8}$ | \\ Cadence A. Kuklinski DO ${ }^{9}$ | Joshua A. Blatter MD, MPH ${ }^{9}$ Jamie Dy MD $^{10}$ | \\ Jordan S. Rettig MD ${ }^{11}$ | Amjad Horani MD ${ }^{9}$ Jane Gross MD PhD ${ }^{12}$ \\ ${ }^{1}$ Department of Pediatrics, Vanderbilt University Medical Center, Nashville, Tennessee \\ ${ }^{2}$ Division of Respiratory Diseases, Boston Children's Hospital, Harvard Medical School, Boston, Massachusetts \\ ${ }^{3}$ Division of Pediatric Respirology, Pulmonary, and Asthma, Department of Pediatrics, University of Alberta, Alberta, Canada \\ ${ }^{4}$ Division of Pediatric Pulmonology, Department of Pediatrics, University of North Carolina School of Medicine, Chapel Hill, North Carolina \\ ${ }^{5}$ Department of Pediatrics, University of Michigan Medical School, Ann Harbor, Michigan \\ ${ }^{6}$ Division of Pediatric Pulmonology, Rady Children's Hospital, University of California San Diego, San Diego, California \\ ${ }^{7}$ Division of Pulmonary Medicine, Department of Pediatrics, University of Cincinnati College of Medicine, Cincinnati, Ohio \\ ${ }^{8}$ Department of Pediatrics, Texas Children's Hospital, Baylor College of Medicine, Houston, Texas \\ ${ }^{9}$ Department of Pediatrics, Washington University School of Medicine, St. Louis, Missouri \\ ${ }^{10}$ Department of Pediatrics, UCSF, San Francisco, California \\ ${ }^{11}$ Department of Anesthesiology, Perioperative and Pain Medicine, Division of Critical Care Medicine, Boston Children's Hospital, Harvard Medical School, \\ Boston, Massachusetts \\ ${ }^{12}$ Division of Pediatric Pulmonary Medicine, Department of Pediatrics, National Jewish Hospital, Denver, Colorado
}

\section{Correspondence}

Paul E. Moore, MD, Vanderbilt University Medical Center, 2200 Children's Way, DOT 11215, Nashville, TN 37232-9500.

Email: paul.moore@vumc.org

\begin{abstract}
The American Thoracic Society Pediatric Core Curriculum updates clinicians annually in pediatric pulmonary disease in a 3 to 4 year recurring cycle of topics. The 2019 course was presented in May during the Annual International Conference. An American Board of Pediatrics Maintenance of Certification module and a continuing medical education exercise covering the contents of the Core Curriculum can be accessed online at www.thoracic.org.

KEYWORDS

lymphatic disorders, obstructive sleep apnea, pediatric sleep, pneumonia, pulmonary vascular malformations, transplant complications
\end{abstract}




\section{Control of breathing in children}

Ryan Perkins and Eliot S. Katz

\section{1 | INTRODUCTION}

The respiratory control system regulates $\mathrm{PO}_{2}, \mathrm{PCO}_{2}$, and $\mathrm{pH}$ within a narrow range, under conditions of changing state, airway resistance, and energy expenditure. The central respiratory pattern generator network is located in the brainstem and receives input from the cortex, hypothalamus, lung, chest wall, extremities, cardiovascular system, emotional centers, chemoreceptors (central/peripheral), and the upper airway. The peripheral chemoreceptors provide considerable input in the seconds following a change in $\mathrm{PCO}_{2}$, but central chemoreceptors play a larger role over periods of minutes to hours.

\section{2 | ANATOMY}

The respiratory rhythm is produced by neural networks located in medullary aggregations termed the Dorsal Respiratory Group and Ventral Respiratory Group (VRG). The respiratory pattern generator contains neurons in the VRG called the pre-Botzinger complex. The nucleus tractus solatarius (NTS) receives signals from the preBotzinger complex and afferent modulation from the periphery. Following integration, signals then project to the upper airway and respiratory muscles. ${ }^{1}$

Central chemoreceptors located on the ventral medulla are sensitive to cerebrospinal fluid (CSF) acidity. CSF and arterial blood are separated by the blood-brain barrier preventing $\mathrm{H}^{+}$and bicarbonate equilibration but allowing $\mathrm{CO}_{2}$ diffusion. Ventilatory drive output is inversely related to $\mathrm{pH}$. Cerebral blood flow is an important determinant of central $\mathrm{CO} 2$ sensitivity. Cerebral blood flow and hypercapneic ventilatory drive are inversely related with decreases in cerebral blood resulting in increased hypercapniec ventilatory drive. Peripheral chemoreceptors in the carotid artery and aortic arch, are sensitive to $\mathrm{P}_{\mathrm{a}} \mathrm{CO}_{2}, \mathrm{P}_{\mathrm{a}} \mathrm{O}_{2}$, and $\mathrm{H}^{+}$and provide afferent signals allowing for breath-by-breath modulation. ${ }^{2}$

\section{3 | PHYSIOLOGY}

During wakefulness and non-rapid eye movement (NREM) sleep, the breathing pattern typically alternates inspirations and expirations without pauses. Respiratory rate and tidal volume are adjusted to maintain $\mathrm{PCO}_{2}, \mathrm{PO}_{2}$, and $\mathrm{pH}$. Breathing is regulated by $\mathrm{P}_{\mathrm{a}} \mathrm{CO}_{2}$, and to a lesser extent by $\mathrm{P}_{\mathrm{a}} \mathrm{O}_{2}{ }^{3}$

The ventilatory control system is modeled by its loop gain, which is the relationship between the ratio of the ventilatory response to a ventilatory perturbation. Respiratory loop gain includes: (a) Controller gain: chemosensitivity: the output of respiratory pattern generators in response to $\mathrm{P}_{\mathrm{a}} \mathrm{CO}_{2}$ and $\mathrm{P}_{\mathrm{a}} \mathrm{O}_{2}$. Chemosensitivity is highest during wakefulness, intermediate during NREM sleep, and lowest during REM sleep; (b) Plant gain: the magnitude of $\mathrm{CO}_{2}$ changes in response to ventilatory drive output reflecting the efficiency of the lungs; (c) Mixing gain: the circulatory delay between the lungs and peripheral chemoreceptors, thoracic blood volume, and brain extracellular fluid volume, that contributes to ventilatory overshooting and undershooting.

Homeostatic oxygen sensing is primarily performed by the carotid body. The contribution of oxygen chemoreceptor input to eupneic ventilation is demonstrated by the decrement in ventilation in response to a single breath of $100 \%$ oxygen. Preterm infants, term infants, and adults who were exposed to a single breath of $100 \%$ oxygen were noted to have reductions in their ventilation of $40 \%, 14 \%, 10 \%$, respectively. This suggests that baseline oxygen tension contributes variability to respiratory drive. Under normocapneic conditions, decreases in $\mathrm{P}_{\mathrm{a}} \mathrm{O}_{2}$ between 100 to 50 torr results in little increase in minute ventilation, but dramatically increases as $\mathrm{P}_{a} \mathrm{O}_{2}$ declines below 50 torr. The increased ventilation is counterbalanced by a decrease in $\mathrm{P}_{\mathrm{a}} \mathrm{CO}_{2}$ which attenuates the increased ventilation. The output of the respiratory pattern generator temporarily increases hypoxemia resulting in increased respiratory muscle stimulation. ${ }^{4}$

\section{4 | SLEEP}

In NREM sleep, ventilation is predominantly chemically controlled. At sleep onset, $\mathrm{P}_{\mathrm{a}} \mathrm{CO}_{2}$ increases and $\mathrm{P}_{\mathrm{a}} \mathrm{O}_{2}$ decreases. In NREM sleep, the emergence of an apneic threshold below eupneic $\mathrm{P}_{\mathrm{a}} \mathrm{CO}_{2}$ predisposes to ventilatory instability. During apnea, $\mathrm{CO}_{2}$ accumulates and oxygenation decreases, leading to chemoreceptor-induced ventilatory overshoot. An increase in $\mathrm{P}_{\mathrm{a}} \mathrm{CO}_{2}$ above apneic threshold is required to reinitiate breathing. ${ }^{5}$ In REM sleep, breathing is influenced by REM processes that lead to irregular rhythm with frequent pauses. Abrupt decreases in motor output to the upper airway and decreased minute ventilation are observed.

Arousal refers to paroxysmal increases of electrocortical activity during sleep, causing sleep fragmentation. There is a shift towards the wakeful level of ventilatory responsiveness and minute ventilation increases. This response far exceeds increases necessary to reverse apnea, leading to relative hypocapnia with decreased upper airway motor tone and facilitating obstructive cycling. ${ }^{6}$ Ventilatory control instability is a major contributor to obstructive sleepdisordered breathing. ${ }^{7}$

\section{5 | INFLUENCE OF EXERCISE}

Exercise is accompanied by increases in oxygen utilization and $\mathrm{CO}_{2}$ production, with minimal change to $\mathrm{P}_{\mathrm{a}} \mathrm{CO}_{2}, \mathrm{P}_{\mathrm{a}} \mathrm{O}_{2}$, or $\mathrm{H}^{+}$until activity levels exceed $60 \%$ of maximum. Below anaerobic threshold, steady state matching of $\mathrm{CO}_{2}$ production and ventilation occurs rapidly. 
Minute ventilation increases linearly until $\sim 60 \%$ of maximal work level, when the production of lactic acid results in markedly increased minute ventilation relative to oxygen consumption, leading to precipitous $\mathrm{P}_{\mathrm{a}} \mathrm{CO}_{2}$ decline. ${ }^{8}$

\section{6 | ALTITUDE}

When ascending to high altitude, the decrease in barometric pressure results in declines in alveolar and arterial oxygen tension. The initial response to hypoxemia is increased ventilation followed by a decline to a new baseline slightly above the eupneic minute ventilation. During the next month, ventilation gradually increases leading to $\mathrm{P}_{\mathrm{a}} \mathrm{CO}_{2}$ reductions that potentially cross the apneic threshold during sleep. Hypoxemia increases hypercapneic ventilatory response (increases Controller Gain), narrowing the $\mathrm{CO}_{2}$ reserve during sleep (the difference between newly reduced baseline $\mathrm{P}_{\mathrm{a}} \mathrm{CO}_{2}$ and the apneic threshold), and making apnea and periodic breathing more likely. Over time, this lowers $\mathrm{CSF} \mathrm{PCO}_{2}$ and ventilation until a new set-point is reached. ${ }^{9}$

\section{7 | CONCLUSION}

Control of breathing is a complex system that is modeled by the loop gain, which reflects the ventilatory response to a ventilatory perturbation. This system thus has the capacity to respond to physiologic changes associated with sleep, exercise, and altitude.

\section{Management of obstructive sleep apnea in children}

Maria L Castro-Codesal and Joanna E MacLean

\section{8 | INTRODUCTION}

The pathophysiology of obstructive sleep apnea (OSA) in children is multifactorial and heterogeneous.

\section{9 | CLINICAL ASSESSMENT}

Identification of children with OSA requires a careful review of symptoms and recognition of risk factors (Table 1). Snoring, though a hallmark, is insufficient to identify OSA. Symptoms that may be informative include observed apneas, difficulty breathing during sleep, daytime sleepiness, and inattentive or hyperactive behavior. These symptoms reflect subjective measures of sleepiness, behavioral impairment, and quality of life at diagnosis and predict their improvement after treatment. ${ }^{10}$ Use of a screening tool, such as the Pediatric Sleep Questionnaire, provides a
TABLE 1 Common risk factors and morbidity associated with obstructive sleep apnea in children

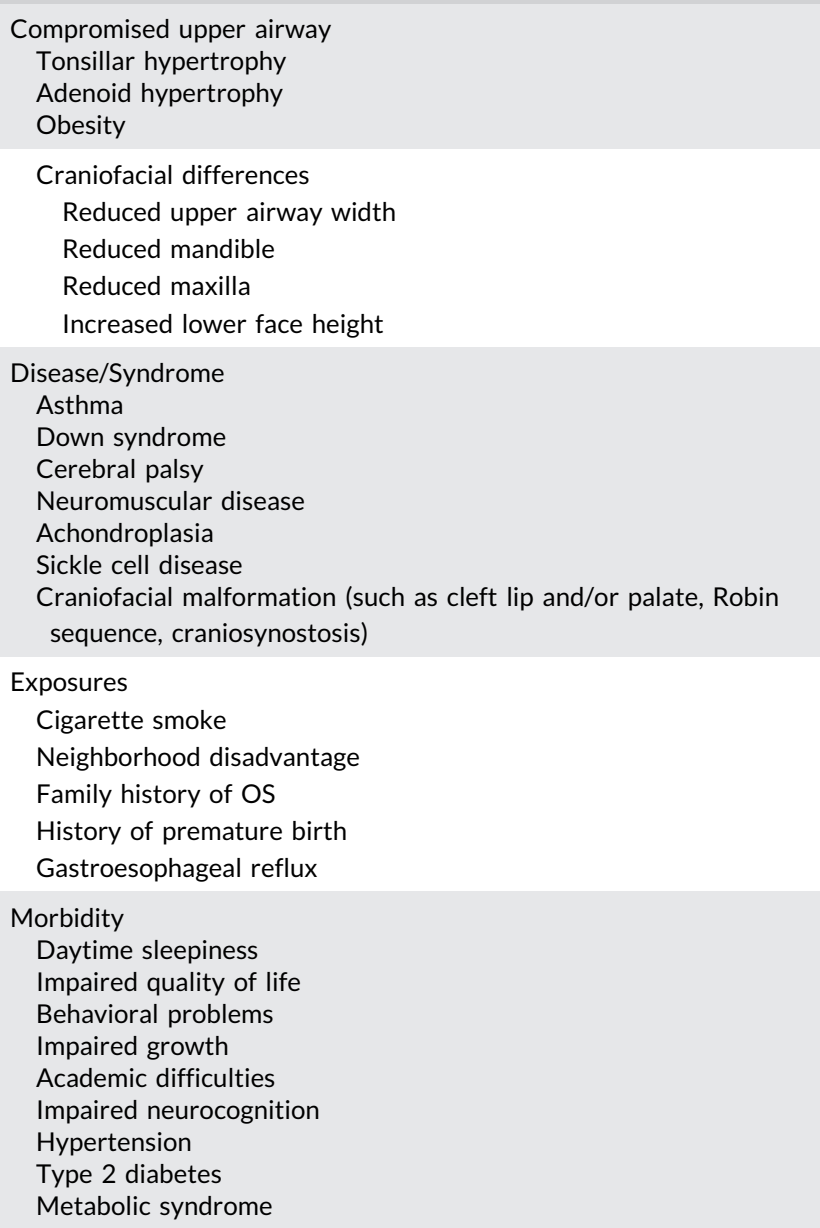

standardized way of assessing symptoms. ${ }^{10}$ Adenoid and/or tonsillar enlargement are an important risk factors for OSA in children; however not all children with adenotonsillar hypertrophy have OSA, ${ }^{11}$ and removal of adenoids or tonsils may not be curative in all children. ${ }^{12}$ Assessment for potential morbidity associated with untreated OSA is an important factor in triaging diagnostic testing and treatment decisions.

\section{0 | DIAGNOSTIC TESTING}

Polysomnography remains the standard for the diagnosis of OSA in children though there is considerable need for more accessible alternatives as access to polysomnography is limited or unavailable in many areas. The polysomnographic diagnosis of OSA relies primarily on the apnea-hypopnea index (AHI) or the obstructive apneahypopnea index $(\mathrm{OAHI})$ where an $\mathrm{AHI} \geq 2$ events/hour or $\mathrm{OAHI} \geq 1$ event/hour indicate OSA in children $>1$ year of age. ${ }^{12}$ These and other polysomnographic variables do not correlate with baseline or posttreatment measures of sleepiness, behavior, or quality of life, ${ }^{10}$ suggesting that current polysomnographic measures may not reflect 
OSA-related morbidity and that polysomnography alone may not well reflect severity of OSA.

Alternatives to polysomnography are used in settings where polysomnography is limited or unavailable. A 2017 position statement from the American Academy of Sleep Medicine concluded that home sleep apnea testing is not recommended for the diagnosis of obstructive sleep apnea in children. ${ }^{13}$ Continuous overnight oximetry recording is more accessible though with multiple ways that the data can be analyzed and reported. Oximetry derived oxygen desaturation index (number of $3 \%$ or greater dips per hour of recording) of 2 events/hour has a high specificity and positive predictive value for a polysomnographic diagnosis of OSA but also a high false negative rate. ${ }^{14}$ Automated methods for the analysis of oximetry appear promising as they allow the inclusion of multiple oximetry parameters. ${ }^{15}$ Both magnetic resonance imaging and drug-induced sleep endoscopy provide information on the site of airway obstruction. However, these tests require special expertise, and are best used selectively after considering sedation risks. ${ }^{16-18}$ The search is still on for biomarkers of OSA and its associated morbidity for use in diagnostic testing.

\section{1 | TREATMENT}

In otherwise healthy children aged 5 to 9 years with mild to moderate OSA, there is moderate quality evidence that adenotonsillectomy provides benefit in terms of quality of life, symptoms, behavior, and improvement in polysomnography measures. ${ }^{19}$ Almost half of the same group of children managed nonsurgically normalized polysomnographic findings at 7 months follow-up so the benefits of surgery vs watchful waiting should be carefully considered; black race, obesity, and $\mathrm{AH}$ above 5 events/hour identified children less likely to normalize $\mathrm{AHI}$ without adenotonsillectomy. ${ }^{19}$ Anti-inflammatory medication, including intranasal steroids, leukotriene receptor antagonists, and azithromycin, may be effective in improving OSA symptoms and reducing $\mathrm{AHI}$ and should be considered when surgery is not an option or not curative. ${ }^{20,21}$ The combination of intranasal steroids and leukotriene receptor antagonist may provide benefit over either alone. ${ }^{22}$ Weight loss or stabilization, while challenging, should be encouraged in children with obesity. ${ }^{20}$ Noninvasive ventilation, including continuous and bilevel positive airway pressure, has challenges with use but is effective in reducing $\mathrm{AHI}^{20}$ There is insufficient evidence to support or refute the use of oral and functional orthopedic appliances for the treatment of OSA in children; these treatment options may be considered in select cases. ${ }^{23}$ Treatment decisions should be individualized with consideration of surgical risks, and benefits as well as burdens of nonsurgical options.

\section{2 | CONCLUSION}

A careful review of symptoms and identification of risk factor is needed to identify children with OSA. Polysomnography remains the standard for the diagnosis of OSA in children. Treatment options include surgery, medications, and noninvasive ventilation.

\section{Complicated pneumonia}

Nour Akil and Charles R. Esther, Jr

\section{3 | INTRODUCTION}

Community acquired pneumonia (CAP) remains an important cause of morbidity and mortality worldwide. ${ }^{24}$ Although CAP generally responds well to therapy with narrow spectrum antibiotics directed against Streptococcus pneumoniae as the most common causative organism, ${ }^{25}$ complicated pneumonia should be suspected if a child with CAP has not responded to standard therapy within 48 to 72 hours, or when comorbidities such as immune deficiency or chronic lung disease are present. ${ }^{26}$ Complicated pneumonia is defined as the presence of one or more of the following complications: pulmonary necrosis, pleural effusion or empyema, lung abscess and bronchopleural fistula. ${ }^{25,26}$ The incidence of complicated pneumonia appears to be increasing over time. ${ }^{24}$

\section{4 | DIAGNOSIS}

The diagnosis and treatment of complicated pneumonia require different strategies from uncomplicated CAP (Figure 1). Initial testing

CAP not responding in 48-72 hours, or significant comorbidities present

Laboratory testing

- $\mathrm{CBC}$ w/ diff, inflammatory markers

- Blood Culture (respiratory culture if possible)<smiles>C1CC23CCC2C13</smiles>

Radiologic evaluation

- Chest radiograph

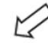

No or small

Moderate or

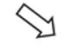

effusion

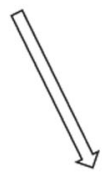
large effusion

Necrosis or<smiles>[C]1=C=C1</smiles>

Chest Ultrasound

VATS or chest tube

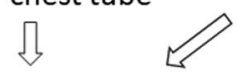

Empiric treatment

- IV $3^{\text {rd }}$ generation cephalosporin

- + IV vanc/clinda if S. aureus suspected

- + oral macrolide if atypicals suspected

\section{Ongoing treatment}

- Narrow antibiotics based on cultures

- Continue IV antibiotics until afebrile

- Then oral antibiotics for 1-4 weeks

FIGURE 1 Simplified algorithm for management of complicated CAP. CAP, community acquired pneumonia; CT, computed tomography; VATS, video assisted thoracoscopic surgery 
should include complete blood count with differential and inflammatory markers, which allow monitoring of treatment responses that can decrease duration of hospitalization and antibiotic courses. ${ }^{26,27}$ Guidelines also recommend obtaining blood cultures in cases of complicated pneumonia, ${ }^{25}$ since bacteremia prevalence has been found to be as high as $7 \%,{ }^{28}$ although bacteremia alone does not make a pneumonia complicated. Further microbiologic testing from samples like sputum, bronchoalveolar lavage, and lung biopsy should be pursued when feasible, since identification of the pathogenic organism allows for tailored antibiotic treatment. Newer molecular techniques such as polymerase chain reaction can increase the likelihood of identifying the causative organism. ${ }^{26}$

Imaging is also recommended for evaluation of possible complicated pneumonia, with a chest radiograph as the initial diagnostic modality. If the chest radiograph suggests the presence of a moderate or large pleural effusion, chest ultrasound is recommended to confirm the presence of fluid as well as provide estimates of the size of effusion and the presence of loculations. ${ }^{29}$ Chest CT with contrast can be considered an alternative radiologic modality, but ultrasound is preferred since $\mathrm{CT}$ does not provide superior diagnostic information yet is more expensive and involves exposure to radiation. ${ }^{29}$ However, contrast enhanced chest CT should be considered if necrotizing pneumonia or lung abscess is suspected.

\section{5 | TREATMENT}

S. pneumoniae remains the most common identified pathogen in complicated pneumonia (Table 2). However, the introduction of pneumococcal conjugate vaccines (PCVs), particularly PCV-13, appears to have decreased the incidence of $S$. pneumoniae and increased the likelihood of infection with other pathogens such as Staphylococcus aureus. ${ }^{26,30}$ When a specific pathogenic organism has not been identified, empiric treatment with a parenteral third generation cephalosporin is recommended. ${ }^{25}$ If clinical features suggest $S$. aureus infection (eg, necrotizing pneumonia), then addition of vancomycin or clindamycin (based on local susceptibility patterns)

TABLE 2 Common microbial etiologies of complicated pneumonia and suggested treatments

\begin{tabular}{ll}
\hline Organism & Antimicrobial treatment \\
\hline Streptococcus pneumoniae & IV 3rd generation cephalosporin \\
\hline Streptococcus pyogenes & IV 3rd generation cephalosporin \\
\hline Staphylococcus aureus & Add IV Clindamycin or Vancomycin or \\
& add Linezolid (2nd line) \\
\hline Mycoplasma pneumoniae & Consider rifampin combination therapy \\
\hline Chlamydia pneumoniae & Add azithromycin \\
\hline Viruses (except influenza) & None \\
\hline Influenza A/B & Add Oseltamivir or Zanamivir \\
\hline
\end{tabular}

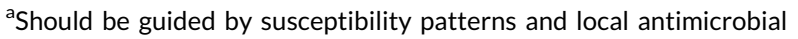
profiles and policies. is recommended, with linezolid as a second-line therapy (Table 2). Addition of macrolide therapy should be considered when atypical organisms such as Chlamydia pneumoniae or Mycoplasma pneumoniae infection are detected by appropriate diagnostic testing (Table 2). There is no consensus on the appropriate length of therapy for complicated pneumonia, with expert recommendations favoring a switch from parenteral to oral therapy after resolution of fever, with a further 1 to 4 weeks of treatment. ${ }^{25,29}$ Longer courses of intravenous antibiotic therapy do not appear to improve outcomes and can be associated with increased complications. ${ }^{31}$

When parapneumonic effusions are present, drainage is recommended unless the effusion is small and not contributing to respiratory symptoms. ${ }^{25,29}$ Both chest thoracoscopic tube drainage with fibrinolysis and video assisted thoracoscopic surgery (VATS) are acceptable options, and patient preference and local expertise should drive decision making. ${ }^{25,29}$ Evidence suggests that VATS may shorten duration of chest tube placement, but studies vary as to whether VATS improves other clinical outcomes such as length of stay, and VATS remains more expensive. ${ }^{32}$ When chest thoracoscopic drainage is performed, evidence suggests that addition of fibrinolytics improves outcomes, ${ }^{33}$ although simple drainage alone can be considered for free-flowing effusions. ${ }^{25}$

\section{6 | OUTCOMES}

Perhaps the most important consideration when managing complicated pneumonia in children is that mortality and long-term morbidity in previously healthy children is very low in developed nations, regardless of the treatment strategy employed. Nevertheless, guidelines remain valuable to help reduce short term morbidity, minimize risk, and promote antibiotic stewardship. Although published guidelines on complicated pneumonia in children are now several years old, recent research suggests that they are still relevant. ${ }^{26,30,31}$ However, further studies are needed to help resolve unanswered questions and ensure that guidelines remain applicable as care changes with time, particularly introduction of effective pneumococcal vaccines.

\section{7 | CONCLUSION}

The diagnosis and treatment of complicated pneumonia require a specific algorithm (Figure 1), with the possible need for microbiologic identification, additional imaging, and alternative treatment regimens. Despite these challenges, mortality and long-term morbidity remain low in developed countries.

\section{Approach to respiratory viruses in children}

Jacob Kaslow and Toby C. Lewis. 


\section{8 | INTRODUCTION}

Respiratory viral infections are a ubiquitous problem with known geographic and seasonal patterns, which can cause a spectrum of clinical disease depending on an individual's distinctive immune condition and environmental exposures. ${ }^{34}$ While most respiratory viral infections are self-limited and localize to the upper respiratory tract, about one-third of infants will also develop lower respiratory tract symptoms, which can become severe. Approximately $80 \%$ of the estimated 2 million global deaths due to respiratory infections between the ages of 0 and 5 years are caused by viral pathogens. Since 2000 , at least six viruses associated with acute respiratory illness have been discovered, including viruses now commonly associated with respiratory disease such as human metapneumovirus. ${ }^{35}$ The suggested approach to respiratory viruses in this section reflects the point of reference of a pulmonary subspecialist assessing children with recurrent or underlying disease, rather than the vantage of a general pediatrician who sees many more children who will not have recurrent problems.

\section{9 | DIAGNOSTIC TESTING}

Most patients are typically diagnosed based on clinical presentation and can be successfully managed with supportive care; thus, specific diagnostic testing is not typically needed. Diagnostic testing may be helpful for patients at highest risk for complications from viral infections, such as those with chronic medical conditions, or for children hospitalized when the cause of wheezing is unclear and identifying a specific virus may help exclude other diagnostic possibilities. Historically, the gold standard for diagnosis of respiratory viral infections was immunofluorescence assays and viral culture, but these have been replaced with multiplex polymerase chain reaction and nucleic acid amplification point of care testing, as these convey improved sensitivity and specificity as well as reduced resulting time. ${ }^{36,37}$

\section{0 | PREVENTION}

Prevention of respiratory viral infections primarily involves measures to reduce exposure such as good hand hygiene and avoidance of contact with other people with acute respiratory symptoms.

Annual vaccination against influenza (flu) is universally recommended in the United States for all children 6 months and over, with particular emphasis on children with underlying respiratory conditions. Egg allergy is no longer considered a contraindication to receiving influenza vaccine. The flu vaccine has been shown to reduce influenza-related hospitalizations and deaths in children. ${ }^{38}$ Three forms of flu vaccine are available: an inactivated influenza vaccine, a recombinant influenza vaccine, and a live attenuated influenza vaccine (LIAV). LIAV is approved for the 2018 to 2019 season, though it is generally not recommended for those with underlying lung conditions and there has been past concern the LAIV has reduced effectiveness compared to the inactivated form. ${ }^{39} \mathrm{~A}$ universal vaccine that would not require annual re-immunization is in development but is not yet commercially available.

There are no available vaccines against respiratory syncytial virus (RSV). Passive immunoprophylaxis with the RSV monoclonal antibody palivizumab is recommended by the American Academy of Pediatrics for infants in the first year of life born before 29 weeks gestation, with chronic lung disease or with hemodynamically significant congenital heart defects. There is indeterminate evidence to support a recommendation for use in patients with other underlying chronic disease such as cystic fibrosis, Down Syndrome, neuromuscular weakness, or those with immune suppression. ${ }^{40}$

Immunization against other childhood viral infections with possible respiratory manifestations, such as measles and varicella, are readily available as part of routine childhood vaccination programs.

\section{1 | TREATMENT}

The foundation of treatment of respiratory viral infections is supportive care with emphasis on hydration, secretion clearance from the nose, and respiratory support. Bronchodilators and systemic steroids are not recommended for healthy patients without underlying respiratory conditions, though there may be a narrow spectrum of patients with severe disease where an empiric trial of these medications might be considered. Viral infections may trigger exacerbations of underlying conditions, such as asthma or cystic fibrosis, necessitating intensified disease-specific therapy. Aerosolized ribavirin is not routinely recommended for RSV infections due to inability to demonstrate consistent efficacy, although it may be considered in patients with severe, life-threatening disease. ${ }^{41}$ Antiviral medications can be helpful for treatment of influenza. Oseltamivir (Tamiflu) has been shown to decrease symptom length by approximately 24 hours in patients with influenza infection although results have not been reproducible in patients with underlying lung disease. ${ }^{42}$

\section{2 | INNOVATIONS}

A universal flu vaccine with antigenic peptide sequences common to a variety of influenza viruses is currently in phase three clinical trials in Europe and phase two clinical trials in the United States. These trials are currently limited to the adult population.

There is a recent increase in RSV vaccine development with more than 28 therapies in predevelopment and at least 17 in clinical development. However, a widely available vaccine is not expected to be available for at least 5 to 10 years. ${ }^{43}$ Additional methods to prevent RSV infection are being explored including a maternal vaccine that is expected to complete phase three clinical trials in 2020. 
There has been significant difficulty in developing both a vaccine and therapy for rhinovirus, due to a variety of antigenically distinct types. Efforts to develop vaccines for other respiratory viruses such as human metapneumovirus have not shown adequate effectiveness.

\section{3 | CONCLUSION}

Respiratory viral infections in children are usually self-limited but can progress to more severe lower respiratory tract infections. Diagnostic testing is indicated in limited clinical situations, and prevention is focused on hand hygiene, immunization, and immunoprophylaxis against RSV in high-risk populations. Treatment options are also limited, although there are ongoing efforts focused on vaccine development.

\section{Lymphatic disorders of the respiratory tract in children}

Katie A. Krone and Annabelle Quizon

\section{4 | INTRODUCTION}

Disorders of the lymphatic system comprise various phenotypes due to defects in development, maturation, and/or function of lymphatic vessels. This clinical spectrum includes, but is not limited to, lymphatic malformations (LM), generalized lymphatic anomaly (GLA), and hereditary as well as sporadic forms of primary lymphedema. Clinical features depend on the structures involved and degree of functional compromise (eg, airway obstruction, dysphagia, phrenic nerve palsy). Recent advances in the genetic characterization of lymphatic disorders reveal mutations affecting proteins involved in the RAS/MAPK and PI3K/AKT pathway, which may account for inherited forms. ${ }^{44,45}$ Nomenclature is evolving as phenotypic distinctions are identified (Table 3) as detailed by the International Society for the Study of Vascular Anomalies in 2018. ${ }^{44,45}$

\section{5 | CLINICAL PRESENTATION}

Common LM, previously referred to as cystic hygroma and lymphangioma, occur in lymphatic-dense areas, with the majority affecting the head and neck. ${ }^{46,47}$ There exist three morphologic types of common LM: macrocystic, microcystic, and combined. Macrocystic lesions are often large multilocular masses located below the mylohyoid muscle. ${ }^{48}$ Microcystic lesions usually appear as noncompressible masses located above the mylohyoid muscle and are often more infiltrative. ${ }^{49}$ Most common LM present within the first 2 years of life and increase in size over time. Symptoms are dictated by the involved structures. The anterior neck is a classic location; approximately $10 \%$ extend into the mediastinum. ${ }^{50}$ Intrapulmonary
TABLE 3 Classification of lymphatic malformations ${ }^{44,45}$ (revised in 2018)

\begin{tabular}{|c|c|}
\hline Lymphatic malformations (LM) & Gene \\
\hline Common (cystic) LM & PIKЗCA \\
\hline \multicolumn{2}{|l|}{ Macrocytic LM } \\
\hline \multicolumn{2}{|l|}{ Microcystic LM } \\
\hline \multicolumn{2}{|l|}{ Mixed cystic LM } \\
\hline \multicolumn{2}{|l|}{ Generalized lymphatic anomaly (GLA) } \\
\hline \multicolumn{2}{|l|}{ Kaposiform lymphangiomatosis (KLA) } \\
\hline \multicolumn{2}{|l|}{ LM in Gorham-Scout Disease } \\
\hline \multicolumn{2}{|l|}{ Channel type LM } \\
\hline \multicolumn{2}{|l|}{ "Acquired" progressive lymphatic anomaly } \\
\hline \multicolumn{2}{|l|}{ Primary lymphedema } \\
\hline Nonne-Milroy syndrome & FLT4/VEGFR3 \\
\hline \multirow[t]{2}{*}{ Primary hereditary lymphedema } & VEGFC \\
\hline & GJC2/Connexin 47 \\
\hline Lymphedema-distichiasis & FOXC2 \\
\hline Hypotrichosis-lymphedema-telangiectasia & SOX18 \\
\hline Primary lymphedema with myelodysplasia & GATA2 \\
\hline $\begin{array}{l}\text { Primary generalized lymphatic anomaly } \\
\text { (Hennekam lymphangiectasia-lymphedema } \\
\text { syndrome) }\end{array}$ & CCBE1 \\
\hline $\begin{array}{l}\text { Microcephaly with or without } \\
\text { chorioretinopathy, lymphedema, or mental } \\
\text { retardation syndrome }\end{array}$ & KJF11 \\
\hline
\end{tabular}

LM are rare. ${ }^{51}$ Complications that may adversely impact the airway include tracheal compression and oropharyngeal infiltration. Chylous pleural and pericardial effusions may develop.

GLA, previously termed lymphangiomatosis, is characterized by multifocal LM affecting thoracic and abdominal viscera as well as bone. ${ }^{52}$ Chylothorax is frequent. A recently described subset of GLA, Kaposiform lymphangiomatosis (KLA), may present with hemorrhagic lymphatic effusions, hemoptysis, coagulopathy and variable thrombocytopenia; this entity portends a poor prognosis, particularly in the setting of pulmonary involvement. Progressive osteolysis of cortical bone distinguishes Gorham-Stout disease from GLA. ${ }^{53,54}$ This disease is also known as "vanishing bone disease" and characterized by LM affecting a single or multiple bones and often neighboring soft tissue. Channel type disorders result from failure to clear lymph due to channel obstruction, dilation, or dysmotility, causing chylothorax, pulmonary lymphangiectasia, and edema of the extremities or body wall. Acquired progressive lymphatic anomaly or so called progressive lymphangioma is a rare benign LM appearing as a solitary plaque on the trunk and limbs possibly as response to injury. ${ }^{55}$ Primary lymphedema leads to abnormal accumulation of interstitial fluid as a result of developmental defects affecting maturation and function of the lymphatic system. The lower extremities are commonly affected. Disease may be primary or associated with syndromic disorders, such as Turner and Nonne-Milroy syndromes. ${ }^{56,57}$ Genetic mutations underlie many types of primary lymphedema as shown in Table 3. 


\section{6 | DIAGNOSIS}

Diagnosis of lymphatic disorders is based primarily on suggestive history and physical examination. ${ }^{58}$ Prenatal detection can be achieved with ultrasound or fetal magnetic resonance imaging (MRI). ${ }^{59,60}$ Doppler ultrasound and MRI are important initial modalities to morphologically characterize the malformation, determine extension, and plan appropriate treatment. ${ }^{61,62}$ Given the lymph component, increased signal on T2-weighted images is characteristic, with gadolinium helping to differentiate LM from venous malformation. In cases in which intralesional bleeding has occurred, a fluid-fluid level may be seen due to the layering of blood and proteinaceous material. Computed tomography is valuable in assessing involvement of adjacent bony structures. Other modalities, such as MR-lymphangiography, overcome technical limitations of traditional contrast lymphangiography in infants and small children. Whereas lymphoscintigraphy remains the gold standard for evaluation of lymph flow, newer modalities such as near-infrared fluorescence lymphatic imaging allow for evaluation in real-time without exposure to radiation or sedation. Histologic confirmation is rarely necessary but should be considered if imaging is equivocal or if malignancy or KLA are suspected.

\section{7 | MANAGEMENT}

Treatment is individualized and should be delivered by an experienced multidisciplinary care team. ${ }^{63}$ Given the potential for cosmetic deformity and encroachment on vital structures, it is essential that management is determined without delay. Approaches include observation, surgery, sclerotherapy, radiofrequency ablation (RFA), laser therapy, and medical management (Table 4). While observation may be appropriate in select cases, combining multiple modalities is often necessary. ${ }^{64}$ Previously, surgical resection was the mainstay of treatment. However, high rates of recurrence prompted identification of alternative management strategies, ${ }^{64}$ and impending airway compromise is the primary indication for prompt surgical intervention. Sclerotherapy is now considered first-line therapy, and commonly used sclerosing agents include OK-432 (Picibanil), doxycycline and bleomycin. ${ }^{65}$ Surgical resection to debulk a lesion may be followed by sclerotherapy to remove residual disease. RFA has shown promise in microcystic LM affecting the oropharyngeal cavity. In addition, the use of medications has evolved in recent years. Sildenafil, a phosphodiesterase- 5 inhibitor, has demonstrated mixed treatment response, ${ }^{66,67}$ whereas sirolimus, a mammalian target of rapamycin (mTOR) inhibitor in which mTOR is a downstream target of the PI3K pathway, has shown benefit for most

TABLE 4 Treatment of lymphatic malformations

\begin{tabular}{|c|c|c|c|}
\hline Treatment & Mechanism & Application & Adverse effects \\
\hline Observation & & $\begin{array}{l}\text { Select cases without cosmetic } \\
\text { deformity or involvement of } \\
\text { vital structures }\end{array}$ & $\begin{array}{l}<50 \% \text { regress } \\
\text { spontaneously }\end{array}$ \\
\hline Surgical resection & & $\begin{array}{l}\text { Complete or partial resection } \\
\text { Relative compression of vital } \\
\text { structures } \\
\text { Status-post failed } \\
\text { Sclerotherapy }\end{array}$ & $\begin{array}{l}\text { Surgical complications } \\
\text { Incomplete resection and } \\
\text { recurrence }\end{array}$ \\
\hline $\begin{array}{l}\text { Sclerotherapy } \\
\text { OK-432 (Picibanil) } \\
\text { Doxycycline } \\
\text { Bleomycin } \\
\text { Ethanol } \\
\text { Sodium tetradecyl } \\
\text { sulfate (STS) }\end{array}$ & $\begin{array}{l}\text { Inflammatory } \\
\text { reaction secondary } \\
\text { to sclerosant and } \\
\text { destruction of LM }\end{array}$ & Macrocystic LM & $\begin{array}{l}\text { May require repeated } \\
\text { treatments } \\
\text { Soft tissue edema } \\
\text { Other AEs specific to } \\
\text { sclerosant used }\end{array}$ \\
\hline Radiofrequency ablation & $\begin{array}{l}\text { Transmission of } \\
\text { energy with } \\
\text { subsequent tissue } \\
\text { destruction and } \\
\text { fibrosis }\end{array}$ & $\begin{array}{l}\text { Microcystic LM } \\
\text { Oropharyngeal LM } \\
\text { GSD }\end{array}$ & $\begin{array}{l}\text { Complications related to } \\
\text { radiation exposure }\end{array}$ \\
\hline Laser therapy & Vaporization of tissue & $\begin{array}{l}\text { Debulk oropharyngeal LM } \\
\text { Cutaneous LM }\end{array}$ & $\begin{array}{l}\text { Scarring } \\
\text { Hypopigmentation }\end{array}$ \\
\hline $\begin{array}{l}\text { Medical management } \\
\text { Sildenafil }\end{array}$ & $\begin{array}{l}\text { Phosphodiesterase- } \\
5 \text { inhibitor }\end{array}$ & $\begin{array}{l}\text { Cystic LM } \\
\text { Orbital LM }\end{array}$ & Nausea \\
\hline Sirolimus & mTOR inhibitor & GLA, KLA, GSD & $\begin{array}{l}\text { Possible increased risk of } \\
\text { infections }\end{array}$ \\
\hline Propanolol & $\begin{array}{l}\beta \text {-adrenergic } \\
\text { receptor antagonist }\end{array}$ & $\begin{array}{l}\text { ? Benefit in mixed } \\
\text { vascular malformations }\end{array}$ & Hair loss \\
\hline
\end{tabular}

Abbreviations: AEs, adverse effects; GLA, generalized lymphatic anomaly; GSD, Gorham-Stout disease; KLA, Kaposiform lymphangiomatosis; LM, lymphatic malformations; mTOR inhibitor, mammalian target of rapamycin inhibitor. 
lymphatic disorders. ${ }^{68-70}$ Randomized controlled trials are needed to guide optimal management.

\section{8 | CONCLUSION}

Ongoing research is essential in understanding the genetic underpinnings of lymphatic disease, identifying predictors of clinical course, and quantifying therapeutic response. Scientific discovery of defective signaling pathways will translate to development of novel molecular targets for treatment. New information will further inform revisions in nomenclature and guide evidence-based evaluation and management strategies.

\section{Pulmonary vascular malformations in children}

Ryne Simpson and Dan Benscoter.

\section{9 | INTRODUCTION}

Vascular anomalies are relatively common among children and can affect capillaries, arteries, veins, or lymphatics.

\section{0 | CLASSIFICATION}

The International Society for the Study of Vascular Anomalies developed an updated classification system in 2018 to provide consistent terminology for clinicians and researchers. ${ }^{71,72}$ Vascular anomalies are classified as proliferative vascular tumors or vascular malformations. Although most vascular anomalies provide little risk to a child's health, pulmonary complications can occur and include airway obstruction, hemorrhage, intrapulmonary shunting, and thrombosis. Because signs and symptoms associated with these anomalies may be subtle, early recognition and appropriate management is critical to prevent potentially devastating consequences.

Vascular malformations arise due to congenital errors of vessel morphogenesis. Malformations tend to grow with the child, in contrast to proliferative vascular tumors, which grow out of proportion to the child and have a predictable growth cycle. Vascular malformations may grow rapidly due to hormonal stimulation or trauma. ${ }^{73}$ The genetic basis for vascular malformations is an emerging field with mutations having been recently discovered for numerous lesions. ${ }^{74}$ Vascular malformations are further classified into four groups (Table 5); however, vascular malformations can also be designated as slow-flow or fast-flow lesions. Slow-flow lesions include venous, capillary, and lymphatic malformations. Fast-flow lesions are primarily arteriovenous malformations (AVMs). This differentiation has important clinical implications, as slow-flow lesions are more likely to be complicated by thrombosis whereas fast-flow lesions are more likely to be
TABLE 5 Vascular anomalies classification ${ }^{71,72}$ (revised in 2018)

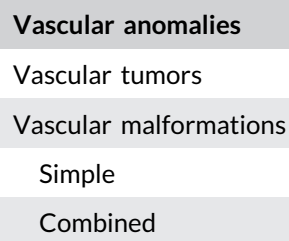

Those of major named vessels

Those associated with other anomalies

complicated by hemorrhage. Vascular malformations may directly impact respiratory physiology or have associated complications affecting the respiratory system.

\section{1 | PULMONARY ARTERIOVENOUS MALFORMATIONS}

AVMs arise due to an error in vascular development during embryogenesis and result in shunting of blood from the arterial to venous circulation. Although many children with pulmonary AVMs are asymptomatic, the right-to-left shunt may result in dyspnea with exertion, cyanosis, or hemoptysis. Larger AVMs also convey a risk for paradoxical emboli to the brain due to the lack of the capillary bed's filtering function.

Contrast echocardiography is a highly sensitive test for detecting pulmonary AVMs in children. ${ }^{75}$ Multidetector computed tomography provides extensive assessment of the vascular architecture of pulmonary AVMs and can be used to plan treatment. Transcatheter embolotherapy is the mainstay of treatment for pulmonary AVMs, though controversy exists in the timing of treatment in children. ${ }^{76}$ Indications for embolization include symptomatic lesions and AVMs with feeding arteries greater than 2 to $3 \mathrm{~mm}$ in diameter which present a greater risk for neurologic complications. There is risk for reperfusion or development of pulmonary collateral vessels after embolotherapy.

Hereditary hemorrhagic telangiectasia (HHT) is an autosomal dominant disorder characterized by mucocutaneous telangiectasias, epistaxis, visceral AVMs and a family history of HHT. Up to $60 \%$ of children with HHT may have a pulmonary AVM, many of which develop after an initial negative screen. ${ }^{77}$ Although recommendations on screening patients with $\mathrm{HHT}$ exist only for adults, ${ }^{78}$ the high prevalence of pulmonary AVMs in children suggests that screening should also be performed at a young age.

\section{2 | VASCULAR MALFORMATIONS ASSOCIATED WITH OTHER ANOMALIES}

Several syndromes associated with vascular malformations convey an increased risk for respiratory complications. Klippel-Trenaunay syndrome (KTS) is a rare syndrome due to complex capillary- 
lymphatic-venous malformations, resulting in overgrowth of soft tissue and bone with limb hypertrophy. Patients with KTS may have ectatic veins connected to central veins, resulting in a predisposition to venous stasis and increased risk for deep vein thrombosis and pulmonary embolism. ${ }^{79}$ Proteus syndrome is an asymmetric overgrowth syndrome associated with complex vascular malformations that can result in thromboembolism due to stasis in the affected limb. Some children with Proteus syndrome also develop bullous lung malformations. Children with CLOVES syndrome (congenital lipomatosis, vascular malformations, epidermal nevi, skeletal/scoliosis abnormalities) may have central or thoracic phlebectasia increasing their risk for pulmonary embolism.

\section{3 | AIRWAY INFANTILE HEMANGIOMAS}

Infantile hemangiomas are proliferative lesions as opposed to true vascular malformations. Airway infantile hemangiomas are typically asymptomatic at birth. A child with a subglottic hemangioma may develop stridor or a croup-like cough during the proliferative phase, typically within the first 6 months of life. The presence of multiple cutaneous hemangiomas in the head and neck region increases the risk of having an airway hemangioma. Propranolol has been shown to be an effective treatment for airway infantile hemangiomas; however, some children may still require surgical intervention. ${ }^{80}$ Clinicians must remain vigilant following treatment as rebound growth can occur after discontinuation of propranolol. ${ }^{81}$

\section{4 | CONCLUSION}

Pulmonary vascular malformations in children include AVMs and malformations associated with other anomalies. Infantile hemangiomas represent proliferative lesions, rather than vascular malformations. Diagnosis and management vary by specific condition.

\section{Pulmonary complications of hematopoietic cell transplant}

David R. Spielberg and Ernestina Melicoff.

\section{5 | INTRODUCTION}

Hematopoietic cell transplant (HCT) is an accepted therapy for various hematologic malignancies, nonmalignant diseases, and solid tumors. Despite advances in the past decades, pulmonary complications remain a significant limitation to success. ${ }^{82}$

Predisposing factors of pulmonary complications include HCT type, autologous vs allogeneic; conditioning regimen, chemotherapy with or without radiation; and pre-transplant pulmonary disease. ${ }^{83}$

\section{6 | ASSESSMENT}

Pretransplant respiratory assessment includes laboratory studies (blood gases, serum chemistries assessing acid-base status, and complete blood count), electrocardiogram, spirometry, ${ }^{84}$ lung volumes, diffusing capacity of the lung for carbon monoxide (DLCO), and 6-minute walk testing. ${ }^{82}$ Chest computed tomography (CT) use should be based on history and clinical findings. Based on the frequency of abnormal findings, routine sinus $\mathrm{CT}$ imaging may be justified. ${ }^{85}$ A number of risk scores have been developed, but none has been validated in children. The lung function score combines the forced expiratory volume in 1 second (FEV1) and DLCO, estimating the risk of mortality and acute respiratory failure. ${ }^{86}$ The pre-transplantation assessment of mortality score utilizes eight clinical factors to predict mortality within the first 2 years. ${ }^{87}$

Pulmonary complications can be divided into those that are infectious and noninfectious. Their clinical diagnosis can be facilitated by the well-known timeline of the most common diseases; early complications occur within 100 days from HCT, while late complications take place beyond 100 days. ${ }^{83}$ Patients can present with various signs of respiratory tract disease. ${ }^{82,83}$ Noninvasive tests can differentiate between upper respiratory tract infections and pulmonary complications. A basic evaluation consists of blood culture, sputum culture, nasopharyngeal swabs, urinary antigens, and chest radiograph. ${ }^{88}$ If symptoms are severe or there is no resolution, a chest $\mathrm{CT}$ is recommended. Flexible bronchoscopy for bronchoalveolar lavage (BAL) is considered a valuable tool in patients with lung infiltrates on imaging. A recent study showed that early bronchoscopy ( $<5$ days) had higher diagnostic yield than late bronchoscopy (78 vs 23\%). ${ }^{88}$ Open lung biopsy can provide an accurate histopathological diagnosis, but due to the associated morbidity, careful patient selection is necessary. ${ }^{89}$

\section{7 | IDIOPATHIC PNEUMONIA SYNDROME}

Idiopathic pneumonia syndrome (IPS) is a common acute noninfectious complication, with an incidence reported to be around $20 \%$ in children. ${ }^{83}$ Clinical manifestations include dyspnea, non-productive cough, and hypoxemia. Pulmonary function testing reveals a restrictive physiology. The diagnosis of IPS requires BAL to be negative for infection. Histopathology of biopsies demonstrates interstitial pneumonia and diffuse alveolar damage. IPS treatment remains supportive, and prognosis is poor in patients who require mechanical ventilation. Other early complications observed in children include veno-occlusive disease, pulmonary edema, and pulmonary hemorrhage. ${ }^{82,83}$

\section{8 | INFECTIOUS COMPLICATIONS}

Infectious complications appear during the different phases postHCT: bacterial infections predominate the pre-engraftment phase, 
fungal infections are seen in those with delayed engraftment, and more than two-thirds of HSV-seropositive patients develop stomatitis. Early CMV reactivation can be seen in $50 \%$ to $80 \%$ of seropositive allogeneic recipients. Ganciclovir and high dose antiCMV IgG are part of the treatment and have led to significant reduction in incidence and mortality. ${ }^{83}$ Post-engraftment, invasive Aspergillus (IA) occurs in $15 \%$ of allogeneic $\mathrm{HCT}$ recipients, and symptoms include fever, pleuritic chest pain, dyspnea, and hemoptysis. Chest $\mathrm{CT}$ findings in IA include the halo sign and air-crescent sign, which are characteristic but not diagnostic. Aspergillus species can be isolated from BAL in $30 \%$ to $50 \%$ of cases.

\section{9 | BRONCHIOLITIS OBLITERANS}

In addition to infectious and acute post-HCT complications, the lung is subject to chronic sequelae of HCT in the setting of chronic graftvs-host disease (GVHD). This typically manifests in the lungs as Bronchiolitis Obliterans (BO) or Bronchiolitis Obliterans Syndrome (BOS), the distinction depending upon the presence of biopsy-proven disease. An initial National Institutes of Health consensus project was reported in 2005 and updated in $2014 .^{90}$ Spirometry is key to the diagnosis of BOS for two reasons: (a) airflow obstruction defines the physiology of the disease; and (b) spirometric changes can present before symptoms, thus providing an opportunity for early intervention. CT is an important supportive diagnostic tool, with welldescribed findings in BOS, but it is not necessary for the diagnosis if a patient has known chronic GVHD of other organ systems. Most importantly, infection must be excluded in the evaluation of a patient with suspect lung GVHD-both because of the ability of infection to mimic the clinical presentation and because of risks of initiating additional immunomodulatory therapies in the setting of infection.

BOS treatment focuses on quelling the immune response. Data on treatment protocols are extremely limited; only a few randomized clinical trials exist, and no studies have prospectively compared different regimens in a head-to-head fashion. A number of clinical trials are ongoing. Therapies range from inhaled corticosteroids to various systemic immunomodulatory therapies, including extracorporeal photopheresis. ${ }^{91}$

\section{0 | CONCLUSION}

Pulmonary complications remain a significant concern after hematopoetic cell transplant. Infectious complications appear during the different stages posttransplant, and BAL is required to rule out infection before the diagnosis of IPS and BO.

\section{Pulmonary complications of solid organ transplant}

Cadence A. Kuklinski and Joshua A. Blatter

\section{1 | INTRODUCTION}

Pulmonologists can help transplant teams to anticipate pulmonary complications based on a patient's history. Patients with evidence of asthma, for example, may require alterations to their maintenance medication plans in the months preceding transplant, with some patients benefiting from short courses of oral corticosteroids. ${ }^{92}$ Avoiding tobacco smoke exposure is particularly important in the transplant setting, as secondhand smoke exposure has been associated with perioperative complications and reduced healthrelated quality of life. ${ }^{93}$ The association between sleep pathology and transplant morbidity has not been confirmed, although obstructive sleep apnea is associated with airway complications in surgical patients.

\section{2 | ASSESSMENT}

At some transplant centers, candidates may undergo a formal assessment of frailty before transplant, and frail patients undergoing transplant have been shown to have worse outcomes. ${ }^{94} \mathrm{Six}$ minute walk testing is useful in predicting transplant mortality, and not just among lung transplant recipients. Even in the absence of a formal frailty assessment, pulmonologists can highlight characteristics that are preoperative red flags, such as deconditioning and malnutrition.

Pulmonary function testing (PFT) can help stratify the pulmonary risk of transplant candidates. PFT abnormalities are relatively common both before (eg, decreased forced vital capacity and forced expiratory volume in 1 second) ${ }^{95}$ and after (eg decreased diffusion of carbon monoxide ${ }^{96}$ heart transplant. PFTs do not dependably predict postsurgical pulmonary complications. ${ }^{97}$ Nevertheless, obtaining pretransplant PFTs with both spirometry and lung volumes can identify existing, previously unknown abnormalities and can be used for comparison if there are respiratory complications after transplant.

There may be relatively low yield in obtaining basic chest imaging before transplant. However, a chest radiograph may help identify previously unknown abnormalities, such as lymphadenopathy, that may demand further evaluation before surgery. While not part of a routine evaluation, polysomnogram, echocardiography, and right-heart catheterization may be obtained if clinically indicated.

\section{3 | INFECTION}

After transplant, the likelihood of pulmonary complications will vary by allograft type, as well as by the length of time following transplant. Kidney transplant recipients, for example, may have relatively low risk of pulmonary infection, due both to the nature of the surgery and to the relatively light immunosuppression needed to sustain the allograft. ${ }^{98}$ Longer surgery duration itself is 
associated with the development of postoperative pulmonary complications such as atelectasis, pneumonia, and respiratory failure. ${ }^{97}$ Among all transplant recipients, common communityacquired infections are the most likely causes of mild illness as time passes and immunosuppression is lightened. ${ }^{99}$ While the possibility of pneumocystis jiroveci pneumonia (PJP) requires vigilance in all solid-organ transplant recipients, PJP is substantially less likely in patients who have consistent adherence to a PJP prophylaxis care plan or are years removed from transplant. ${ }^{100}$ Tuberculosis is also an important consideration in the immunosuppressed population, and both tuberculin skin testing and interferon-gamma release assay testing may be useful in an infectious workup. ${ }^{101}$

CMV- and EBV-mediated disease can occur either early or late after transplant. CMV infections can occur even in patients who adhere to a prophylaxis plan and can be considered in patients with a wide array of pulmonary and gastrointestinal symptoms. Posttransplant lymphoproliferative disorder (PTLD) is associated with B cell proliferation due to EBV infection in immunosuppressed hosts. In suspected EBV+PTLD, the EBV viral load is often elevated.

\section{4 | INTERVENTIONS}

Pulmonologists can also identify interventions to prevent or reduce pulmonary complications after solid organ transplant. Patients with neuromuscular weakness are likely to benefit from mechanical insufflation/exsufflation, ${ }^{102}$ and patients with limited mobility due to postoperative pain may benefit from airway clearance. Pain management should strike a balance between respiratory depression and sufficient analgesia and not reduce participation in postoperative pulmonary rehabilitation. Although nutritional support has not been shown to reduce the incidence of pulmonary complications, there is an established association between low albumin levels and pulmonary morbidity. Moreover, initiation of nasogastric feeding can help to protect patients with dysphagia from developing pulmonary complications after surgery. ${ }^{97}$

\section{5 | CONCLUSION}

The pulmonologist plays an important role in evaluating complications following solid organ transplant. Assessment includes careful review of history, pulmonary function testing before and after transplant, and imaging as clinically indicated. Infectious risks vary by allograft time and length of time following transplant. Therapeutic interventions may prevent or reduce pulmonary complications.

\section{ORCID}

Paul E. Moore (D) http://orcid.org/0000-0001-5123-207X Debra Boyer (D) http://orcid.org/0000-0003-4501-314X
Eliot S. Katz (D) http://orcid.org/0000-0003-2771-0814

Nour Akil (iD http://orcid.org/0000-0002-6688-5177

David R. Spielberg (D) http://orcid.org/0000-0002-3720-6307

\section{REFERENCES}

1. Ikeda $\mathrm{K}$, Kawakami $\mathrm{K}$, Onimaru $\mathrm{H}$, et al. The respiratory control mechanisms in the brainstem and spinal cord: integrative views of the neuroanatomy and neurophysiology. J Physiol Sci. 2016;67: 45-62.

2. Smith CA, Forster HV, Blain GM, Dempsey JA. An interdependent model of central/peripheral chemoreception: Evidence and implications for ventilatory control. Respir Physiol Neurobiol. 2010;173: 288-297.

3. Dempsey JA, Smith CA. Pathophysiology of human ventilatory control. Eur Respir J. 2014;44:495-512.

4. Dempsey JA, Morgan BJ. Humans in hypoxia: a conspiracy of maladaptation?! Physiology. 2015;30:304-316.

5. Eckert DJ. Phenotypic approaches to obstructive sleep apnoea new pathways for targeted therapy. Sleep Med Rev. 2018;37:45-59.

6. Amatoury J, Azarbarzin A, Younes M, Jordan AS, Wellman A, Eckert DJ. Arousal intensity is a distinct pathophysiological trait in obstructive sleep apnea. Sleep. 2016;39:2091-2100.

7. Katz ES, D'Ambrosio CM. Pathophysiology of pediatric obstructive sleep apnea. Proc Am Thorac Soc. 2008;5:253-262.

8. Forster HV, Haouzi P, Dempsey JA. Control of breathing during exercise. Compr Physiol. 2012;2:743-777.

9. Ainslie PN, Lucas SJE, Burgess KR. Breathing and sleep at high altitude. Respir Physiol Neurobiol. 2013;188:233-256.

10. Rosen CL, Wang R, Taylor HG, et al. Utility of symptoms to predict treatment outcomes in obstructive sleep apnea syndrome. Pediatrics. 2015;135(3):e662-e671.

11. Papaioannou G, Kambas I, Tsaoussoglou M, PanaghiotopoulouGartagani P, Chrousos G, Kaditis AG. Age-dependent changes in the size of adenotonsillar tissue in childhood: implications for sleepdisordered breathing. J Pediatr. 2013;162(2):269-274.

12. Marcus $\mathrm{CL}$, Moore $\mathrm{RH}$, Rosen $\mathrm{CL}$, et al. $\mathrm{A}$ randomized trial of adenotonsillectomy for childhood sleep apnea. $N$ Engl J Med. 2013;368(25):2366-2376

13. Kirk V, Baughn J, D'Andrea L, et al. American academy of sleep medicine position paper for the use of a home sleep apnea test for the diagnosis of osa in children. J Clin Sleep Med. 2017;13(10): 1199-1203.

14. Nixon GM, Davey MJ, Weichard AJ, Horne RSC. Oximetry for suspected obstructive sleep apnea-does removal of awake data affect the result? Pediatr Pulmonol. 2016;51(12):1409-1413.

15. Hornero R, Kheirandish-Gozal L, Gutiérrez-Tobal GC, et al. Nocturnal oximetry-based evaluation of habitually snoring children. Am J Respir Crit Care Med. 2017;196(12):1591-1598.

16. Manickam PV, Shott SR, Boss EF, et al. Systematic review of site of obstruction identification and non-cpap treatment options for children with persistent pediatric obstructive sleep apnea. Laryngoscope. 2016;126(2):491-500.

17. Collu MA, Esteller E, Lipari F, et al. A case-control study of druginduced sleep endoscopy (dise) in pediatric population: a proposal for indications. Int J Pediatr Otorhinolaryngol. 2018; 108:113-119.

18. Fleck RJ, Shott SR, Mahmoud M, Ishman SL, Amin RS, Donnelly LF. Magnetic resonance imaging of obstructive sleep apnea in children. Pediatr Radiol. 2018;48(9):1223-1233.

19. Venekamp RP, Hearne BJ, Chandrasekharan D, Blackshaw $H$, Lim J, Schilder AG. Tonsillectomy or adenotonsillectomy versus non-surgical management for obstructive sleep-disordered 
breathing in children. Cochrane Database Syst Rev. 2015;10: CD011165.

20. Whitla L, Lennon P. Non-surgical management of obstructive sleep apnoea: A review. Paediatr Int Child Health. 2017;37(1):1-5.

21. Sakarya EU, Bayar Muluk N, Sakalar EG, et al. Use of intranasal corticosteroids in adenotonsillar hypertrophy. J Laryngol Otol. 2017; 131(5):384-390.

22. Yang DZ, Liang J, Zhang F, Yao HB, Shu Y. Clinical effect of montelukast sodium combined with inhaled corticosteroids in the treatment of OSAS children. Medicine. 2017;96(19):e6628.

23. Carvalho FR, Lentini-Oliveira DA, Prado LB, Prado GF, Carvalho LB. Oral appliances and functional orthopaedic appliances for obstructive sleep apnoea in children. Cochrane Database Syst Rev. 2016; 10:CD005520.

24. Fletcher MA, Schmitt HJ, Syrochkina M, Sylvester G. Pneumococcal empyema and complicated pneumonias: global trends in incidence, prevalence, and serotype epidemiology. Eur J Clin Microbiol Infect Dis. 2014;33:879-910.

25. Bradley JS, Byington CL, Shah SS, et al. The management of community-acquired pneumonia in infants and children older than 3 months of age: Clinical Practice Guidelines by the Pediatric Infectious Diseases Society and the Infectious Diseases Society of America. Clin Infect Dis. 2011;53:e25-e76.

26. Tracy MC, Mathew R. Complicated pneumonia: current concepts and state of the art. Curr Opin Pediatr. 2018;30:384-392.

27. Baer G, Baumann P, Buettcher M, et al. Procalcitonin guidance to reduce antibiotic treatment of lower respiratory tract infection in children and adolescents (ProPAED): a randomized controlled trial. PLoS One. 2013;8:e68419.

28. Myers AL, Hall M, Williams DJ, et al. Prevalence of bacteremia in hospitalized pediatric patients with community-acquired pneumonia. Pediatr Infect Dis J. 2013;32:736-740.

29. Balfour-Lynn IM, Paediatric Pleural Diseases Subcommittee of the BTSSoCC. BTS guidelines for the management of pleural infection in children. Thorax. 2005;60(Suppl 1):i1-i21.

30. Wiese AD, Griffin MR, Zhu Y, Mitchel EF Jr., Grijalva CG. Changes in empyema among U.S. children in the pneumococcal conjugate vaccine era. Vaccine. 2016;34:6243-6249.

31. Shah SS, Srivastava R, Wu S, et al. Intravenous versus oral antibiotics for postdischarge treatment of complicated pneumonia. Pediatrics. 2016;138:e20161692.

32. Shah SS, Ten Have TR, Metlay JP. Costs of treating children with complicated pneumonia: a comparison of primary video-assisted thoracoscopic surgery and chest tube placement. Pediatr Pulmonol. 2010;45:71-77.

33. Thomson AH, Hull J, Kumar MR, Wallis C, Balfour Lynn IM. Randomised trial of intrapleural urokinase in the treatment of childhood empyema. Thorax. 2002;57:343-347.

34. Charlton CL, Babady E, Ginocchio CC, et al. Practical guidance for clinical microbiology laboratories: viruses causing acute respiratory tract infections. Clin Microbiol Rev. 2018;32:e00042-18.

35. Mahony JB. Detection of respiratory viruses by molecular methods. Clin Microbiol Rev. 2008;21:716-747.

36. Gill PJ, Richardson SE, Ostrow O, Friedman JN. Testing for respiratory viruses in children: to swab or not to swab. JAMA Pediatr. 2017;171:798-804.

37. Das S, Dunbar S, Tang YW. Laboratory diagnosis of respiratory tract infections in children - the state of the art. Front Microbiol. 2018;9:2478.

38. Flannery B, Reynolds SB, Blanton L, et al. Influenza vaccine effectiveness against pediatric deaths: 2010-2014. Pediatrics. 2017; 139:e20164244.

39. Chung JR, Flannery B, Ambrose CS, et al. Live attenuated and inactivated influenza vaccine effectiveness. Pediatrics. 2019;143 e20182094.
40. American Academy of Pediatrics Committee on Infectious D. Updated guidance for palivizumab prophylaxis among infants and young children at increased risk of hospitalization for respiratory syncytial virus infection. Pediatrics. 2014;134:e620-e638.

41. American Academy of Pediatrics. Respiratory syncytial virus. In: Kimberlin DW, Brady MT, Jackson MA, Long SS, eds. Red Book: 2018 Report of the Committee on Infectious Diseases. 31st ed. Itasca, IL: American Academy of Pediatrics; 2018.

42. Malosh RE, Martin ET, Heikkinen T, Brooks WA, Whitley RJ, Monto AS. Efficacy and safety of oseltamivir in children: systematic review and individual patient data meta-analysis of randomized controlled trials. Clin Infect Dis. 2018;66:1492-1500.

43. Simões EAF, Bont L, Manzoni $P$, et al. Past, present and future approaches to the prevention and treatment of respiratory syncytial virus infection in children. Infect Dis Ther. 2018;7:87-120.

44. Perkins JA. New frontiers in our understanding of lymphatic malformations of the head and neck: natural history and basic research. Otolaryngol Clin North Am. 2018;51(1):147-158.

45. Brouillard P, Boon L, Vikkula M. Genetics of lymphatic anomalies. J Clin Invest. 2014;124(3):898-904.

46. Elluru RG, Azizkhan RG. Cervicofacial vascular anomalies. Ii. Vascular malformations. Semin Pediatr Surg. 2006;15(2):133-139.

47. Hochman M, Adams DM, Reeves TD. Current knowledge and management of vascular anomalies, ii: Malformations. Arch Facial Plast Surg. 2011;13(6):425-433.

48. de Serres LM, Sie KCY, Richardson MA. Lymphatic malformations of the head and neck: a proposal for staging. Arch Otolaryngol Head Neck Surg. 1995;121(5):577-582.

49. Elluru RG, Balakrishnan K, Padua HM. Lymphatic malformations: diagnosis and management. Semin Pediatr Surg. 2014;23(4):178-185.

50. Brown LR, Reiman HM, Rosenow EC 3rd, Gloviczki PM, Divertie MB. Intrathoracic lymphangioma. Mayo Clin Proc. 1986;61(11): 882-892

51. Drut R, Mosca HH. Intrapulmonary cystic lymphangioma. Pediatr Pulmonol. 1996;22(3):204-206.

52. Faul JL, Berry GJ, Colby TV, et al. Thoracic lymphangiomas, lymphangiectasis, lymphangiomatosis, and lymphatic dysplasia syndrome. Am J Respir Crit Care Med. 2000;161(3 Pt 1):10371046.

53. Aviv RI, McHugh K, Hunt J. Angiomatosis of bone and soft tissue: a spectrum of disease from diffuse lymphangiomatosis to vanishing bone disease in young patients. Clin Radiol. 2001;56(3): 184-190.

54. Nikolaou VS, Chytas D, Korres D, Efstathopoulos N. Vanishing bone disease (gorham-stout syndrome): a review of a rare entity. World J Orthop. 2014;5(5):694-698.

55. Larkin SC, Wentworth AB, Lehman JS, Tollefson MM. A case of extensive acquired progressive lymphangioma. Pediatr Dermatol. 2018;35(4):486-489.

56. Connell F, Brice G, Mortimer P. Phenotypic characterization of primary lymphedema. Ann N Y Acad Sci. 2008;1131:140-146.

57. Toro-Solá MA. Distichiasis-lymphedema syndrome and the turner phenotype. Bol Asoc Med P R. 1991;83(12):543-544.

58. Wassef M, Blei F, Adams D, et al. Vascular anomalies classification: recommendations from the international society for the study of vascular anomalies. Pediatrics. 2015;136(1):e203-e214.

59. Inde Y, Yamagishi E, Kawabata I, Sekiguchi A, Nakai A, Takeshita T. Morphological changes observed via fetal ultrasound in prenatally diagnosed and isolated congenital lymphangiomas: three case reports. J Med Ultrason. 2013;40(3):265-269.

60. Koelblinger C, Herold C, Nemec S, et al. Fetal magnetic resonance imaging of lymphangiomas. J Perinat Med. 2013; 41(4):437-443.

61. Merrow AC, Gupta A, Patel MN, Adams DM. 2014 revised classification of vascular lesions from the international society for 
the study of vascular anomalies: radiologic-pathologic update. Radiographics. 2016;36(5):1494-1516.

62. Steinklein JM, Shatzkes DR. Imaging of vascular lesions of the head and neck. Otolaryngol Clin North Am. 2018;51(1):55-76.

63. Waner M, O TM. Multidisciplinary approach to the management of lymphatic malformations of the head and neck. Otolaryngol Clin North Am. 2018;51(1):159-172.

64. Greene AK, Perlyn CA, Alomari Al. Management of lymphatic malformations. Clin Plast Surg. 2011;38(1):75-82.

65. Smith MC, Zimmerman MB, Burke DK, Bauman NM, Sato Y, Smith $\mathrm{RJH}$. Efficacy and safety of ok-432 immunotherapy of lymphatic malformations. Laryngoscope. 2009;119(1):107-115.

66. Danial C, Tichy AL, Tariq U, et al. An open-label study to evaluate sildenafil for the treatment of lymphatic malformations. J Am Acad Dermatol. 2014;70(6):1050-1057.

67. Swetman GL, Berk DR, Vasanawala SS, Feinstein JA, Lane AT, Bruckner AL. Sildenafil for severe lymphatic malformations. N Engl J Med. 2012;366(4):384-386.

68. Triana $\mathrm{P}$, Dore $\mathrm{M}$, Cerezo VN, et al. Sirolimus in the treatment of vascular anomalies. Eur J Pediatr Surg. 2017;27(1):86-90.

69. Adams DM, Trenor CC 3rd, Hammill AM, et al. Efficacy and safety of sirolimus in the treatment of complicated vascular anomalies. Pediatrics. 2016;137(2):e20153257.

70. Hammill AM, Wentzel M, Gupta A, et al. Sirolimus for the treatment of complicated vascular anomalies in children. Pediatr Blood Cancer. 2011;57(6):1018-1024.

71. Wassef M, Blei F, Adams D, et al. Vascular anomalies classification: recommendations from the International Society for the Study of Vascular Anomalies. Pediatrics. 2015;136(1):e203-e214.

72. ISSVA Classification of Vascular Anomalies @2018 International Society for the Study of Vascular Anomalies Available at "issva.org/ classification" Accessed [June 13, 2019]

73. Merrow AC, Gupta A, Patel MN, Adams DM. 2014 Revised classification of vascular lesions from the International Society for the Study of Vascular Anomalies: radiologic-pathologic update. Radiographics. 2016;36(5):1494-1516.

74. Greene AK, Goss JA. Vascular anomalies: from a clinicohistologic to a genetic framework. Plast Reconstr Surg. 2018;141(5): 709e-717e.

75. Al-Saleh S, Dragulescu A, Manson D, et al. Utility of contrast echocardiography for pulmonary arteriovenous malformation screening in pediatric hereditary hemorrhagic telangiectasia. J Pediatr. 2012;160(6):1039-1043.e1.

76. Faughnan ME, Thabet A, Mei-Zahav M, et al. Pulmonary arteriovenous malformations in children: outcomes of transcatheter embolotherapy. J Pediatr. 2004;145(6):826-831.

77. Mowers KL, Sekarski L, White AJ, Grady RM. Pulmonary arteriovenous malformations in children with hereditary hemorrhagic telangiectasia: a longitudinal study. Pulm Circ. 2018;8(3):2045894018786696.

78. Faughnan ME, Palda VA, Garcia-Tsao G, et al. International guidelines for the diagnosis and management of hereditary haemorrhagic telangiectasia. J Med Genet. 2011;48(2):73-87.

79. Nakano TA, Zeinati C. Venous thromboembolism in pediatric vascular anomalies. Front Pediatr. 2017;5:158.

80. Darrow DH. Management of infantile hemangiomas of the airway. Otolaryngol Clin North Am. 2018;51(1):133-146.

81. Shah SD, Baselga E, McCuaig C, et al. Rebound growth of infantile hemangiomas after propranolol therapy. Pediatrics. 2016;137(4): e20151754.

82. Michelson PH, Goyal R, Kurland G. Pulmonary complications of haematopoietic cell transplantation in children. Paediatr Respir Rev. 2007;8:46-61.
83. Kaya Z, Weiner DJ, Yilmaz D, Rowan J, Goyal RK. Lung function, pulmonary complications, and mortality after allogeneic blood and marrow transplantation in children. Biol Blood Marrow Transplant. 2009;15:817-826.

84. Srinivasan A, Srinivasan S, Sunthankar S, et al. Pre-hematopoietic stem cell transplant lung function and pulmonary complications in children. Ann Am Thorac Soc. 2014;11(10):1576-1585.

85. Kasow KA, Krueger J, Srivastava DK, et al. Clinical utility of computed tomography screening of chest, abdomen, and sinuses before hematopoietic stem cell transplantation: the St. Jude experience. Biol Blood Marrow Transplant. 2009;15:490-495.

86. Parimon T, Madtes DK, Au DH, Clark JG, Chien JW. Pretransplant lung function, respiratory failure, and mortality after stem cell transplantation. Am J Respir Crit Care Med. 2005;172:384-390.

87. Au BKC, Gooley TA, Armand P, et al. Reevaluation of the pretransplant assessment of mortality score after allogeneic hematopoietic transplantation. Biol Blood Marrow Transplant. 2015; 21:848-854.

88. Lucena CM, Torres A, Rovira M, et al. Pulmonary complications in hematopoietic SCT: a prospective study. Bone Marrow Transplant. 2014;49:1293-1299.

89. Hayes-Jordan A, Benaim E, Richardson S, et al. Open lung biopsy in pediatric bone marrow transplant patients. J Pediatr Surg. 2002; 37(3):446-452.

90. Jagasia MH, Greinix HT, Arora M, et al. National Institutes of Health Consensus Development Project on Criteria for Clinical Trials in Chronic Graft-versus-Host Disease: I. The 2014 Diagnosis and Staging Working Group report. Biol Blood Marrow Transplant. 2015;21(3):389-401.e1.

91. Bergeron A, Cheng GS. Bronchiolitis obliterans syndrome and other late pulmonary complications after allogeneic hematopoietic stem cell transplantation. Clin Chest Med. 2017;38(4):607-621.

92. National Asthma Education and Prevention Program. Expert Panel Report 3 (EPR-3): guidelines for the diagnosis and management of asthma-summary report 2007. J Allergy Clin Immunol. 2007;120: S94-S138.

93. Chiswell C, Akram Y. Impact of environmental tobacco smoke exposure on anaesthetic and surgical outcomes in children: a systematic review and meta-analysis. Arch Dis Child. 2017;102: 123-130.

94. Jha SR, Hannu MK, Chang S, et al. The prevalence and prognostic significance of frailty in patients with advanced heart failure referred for heart transplantation. Transplantation. 2016;100: 429-436.

95. Ravenscraft SA, Gross CR, Kubo SH, et al. Pulmonary function after successful heart transplantation. Chest. 1993;103:54-58.

96. Ulrik CS, Carlsen J, Arendrup H, Aldershvile J. Pulmonary function in chronic heart failure. Changes after heart transplantation. Scand Cardiovasc J. 1999;33:131-136.

97. Qaseem A, Snow V, Fitterman N, et al. Risk assessment for and strategies to reduce perioperative pulmonary complications for patients undergoing noncardiothoracic surgery: a guideline from the American College of Physicians. Ann Intern Med. 2006; 144:575-580.

98. Kotloff RM, Ahya VN, Crawford SW. Pulmonary complications of solid organ and hematopoietic stem cell transplantation. Am J Respir Crit Care Med. 2004;170:22-48.

99. Green M. Introduction: infections in solid organ transplantation. Am J Transplant. 2013;13(Suppl 4):3-8.

100. Lee SH, Huh KH, Joo DJ, et al. Risk factors for Pneumocystis jirovecii pneumonia (PJP) in kidney transplantation recipients. Sci Rep. 2017;7:1571. 
101. Horne DJ, Narita M, Spitters CL, Parimi S, Dodson S, Limaye AP. Challenging issues in tuberculosis in solid organ transplantation. Clin Infect Dis. 2013;57:1473-1482.

102. Chatwin M, Ross E, Hart N, Nickol AH, Polkey MI, Simonds AK. Cough augmentation with mechanical insufflation/exsufflation in patients with neuromuscular weakness. Eur Respir J. 2003;21: 502-508.
How to cite this article: Moore PE, Boyer D, Perkins R, et al. American thoracic society 2019 pediatric core curriculum. Pediatric Pulmonology. 2019;54:1880-1894.

https://doi.org/10.1002/ppul.24482 